\title{
Tiotropium/Olodaterol Decreases Exacerbation Rates Compared with Tiotropium in a Range of Patients with COPD: Pooled Analysis of the TONADO ${ }^{\circledR}$ / DYNAGITO $^{\circledR}$ Trials
}

Jadwiga A. Wedzicha · Roland Buhl · Dave Singh • Claus F. Vogelmeier •

Alberto de la $\mathrm{Hoz} \cdot$ Wenqiong Xue $\cdot$ Antonio Anzueto •

Peter M. A. Calverley

Received: May 20, 2020 / Published online: August 10, 2020

(c) The Author(s) 2020

\section{ABSTRACT}

Introduction: Previous studies demonstrated that tiotropium/olodaterol reduced rates of exacerbations in patients with chronic obstructive pulmonary disease (COPD). However, this should be examined in a wider population.

Methods: This post hoc analysis pooled data from TONADO $^{\circledR} 1+2$ and DYNAGITO ${ }^{\circledR}$, three

Digital Features To view digital features for this article go to https://doi.org/10.6084/m9.figshare.12619259.

Electronic supplementary material The online version of this article (https://doi.org/10.1007/s12325020-01438-3) contains supplementary material, which is available to authorized users.

\section{J. A. Wedzicha $(\bowtie)$}

Respiratory Division, National Heart and Lung Institute, Imperial College London, London, UK

e-mail: j.wedzicha@imperial.ac.uk

R. Buhl

Johannes Gutenberg University Mainz, Mainz,

Germany

D. Singh

Medicines Evaluation Unit, University of

Manchester, Manchester University NHS

Foundation Trust, Manchester, UK

\section{F. Vogelmeier}

Department of Medicine, Pulmonary and Critical Care Medicine, University Medical Center Giessen and Marburg, Philipps University of Marburg, Member of the German Center for Lung Research (DZL), Marburg, Germany 52-week, parallel-group, randomised, doubleblind, phase III trials investigating patients with moderate-to-very severe COPD, with and without previous exacerbations, who received tiotropium/olodaterol $5 / 5 \mu \mathrm{g}$ or tiotropium $5 \mu \mathrm{g}$. Subgroup analyses were conducted on patients stratified by exacerbation history, Global Initiative for Chronic Obstructive Lung Disease (GOLD) stage 2-4 disease severity and baseline inhaled corticosteroid (ICS) use.

Results: In 9942 patients, tiotropium/olodaterol was associated with lower rates of moderate/severe exacerbations (0.68 vs. 0.77 per patient-year; rate ratio (RR) vs. tiotropium 0.89, 95\% confidence interval (CI) $0.84,0.95$;

\footnotetext{
A. de la $\mathrm{Hoz}$

Boehringer Ingelheim International $\mathrm{GmbH}$, Ingelheim am Rhein, Germany

W. Xue

Boehringer Ingelheim Pharmaceuticals Inc., Ridgefield, CT, USA
}
A. Anzueto
Department of Pulmonary Medicine and Critical Care, University of Texas Health Sciences Center and South Texas Veterans Health Care System, San Antonio, TX, USA
P. M. A. Calverley Clinical Science Centre, Institute of Ageing and Chronic Disease, University of Liverpool, Liverpool, UK 
$P=0.0003)$ and exacerbations requiring hospitalisation (0.11 vs. 0.13 per patient-year; RR $0.86,95 \%$ CI $0.75,0.99 ; P=0.0380$ ) versus tiotropium. Lower rates of moderate/severe exacerbations with tiotropium/olodaterol versus tiotropium were evident in patients with $0-1$ moderate exacerbation in the previous year (0.54 vs. 0.60 per patient-year; RR 0.90, 95\% CI $0.82,0.98 ; P=0.0187$ ) and at least two moderate or at least one severe exacerbation(s) in the previous year (0.97 vs. 1.09 per patient-year; RR $0.89,95 \%$ CI $0.82,0.97 ; P=0.0096)$. In patients with GOLD 2 and GOLD 3 COPD, moderate/severe exacerbation rates were lower with tiotropium/olodaterol versus tiotropium; GOLD 4 patients showed negligible difference between treatments. When evaluating patients by baseline ICS use, there was a significantly lower rate of moderate/severe exacerbations with tiotropium/olodaterol versus tiotropium in patients receiving ICS.

Conclusions: Tiotropium/olodaterol decreased the rate of moderate/severe exacerbations and exacerbations leading to hospitalisation versus tiotropium. Results from this large, pooled, post hoc analysis support the use of dual bronchodilation with tiotropium/olodaterol in a broad range of patients, reflective of patients with COPD in clinical practice.
Trial Registration: TONADO ${ }^{\circledR} 1$ (ClinicalTrials.gov: NCT01431274); TONADO ${ }^{\circledR} 2$ (ClinicalTrials.gov: $\quad$ NCT01431287); $\quad$ DYNAGITO $^{\circledR}$ (ClinicalTrials.gov: NCT02296138).

Plain Language Summary: People with chronic obstructive pulmonary disease (COPD) may have times when their symptoms worsen, known as exacerbations. This may mean that they need to take additional medications, such as antibiotics or oral steroids. Studies have shown that a combination of two types of inhaled medicine-tiotropium and olodaterol-can help to reduce exacerbations in some people. To see if this is also the case across a larger and more diverse range of people, we combined the results from three studies (TONADO ${ }^{\circledR} 1+2$ and DYNAGITO ${ }^{\circledR}$ ) that looked at people who were taking tiotropium and olodaterol together and people who were taking tiotropium alone. We showed that, across a wide range of people, treatment with tiotropium/olodaterol was generally better at reducing exacerbations than tiotropium. Tiotropium/olodaterol also decreased the number of exacerbations that led to hospitalisation compared with tiotropium. Overall, our results support the use of combined tiotropium/olodaterol in people at different stages of COPD.

\section{Graphical Abstract:}

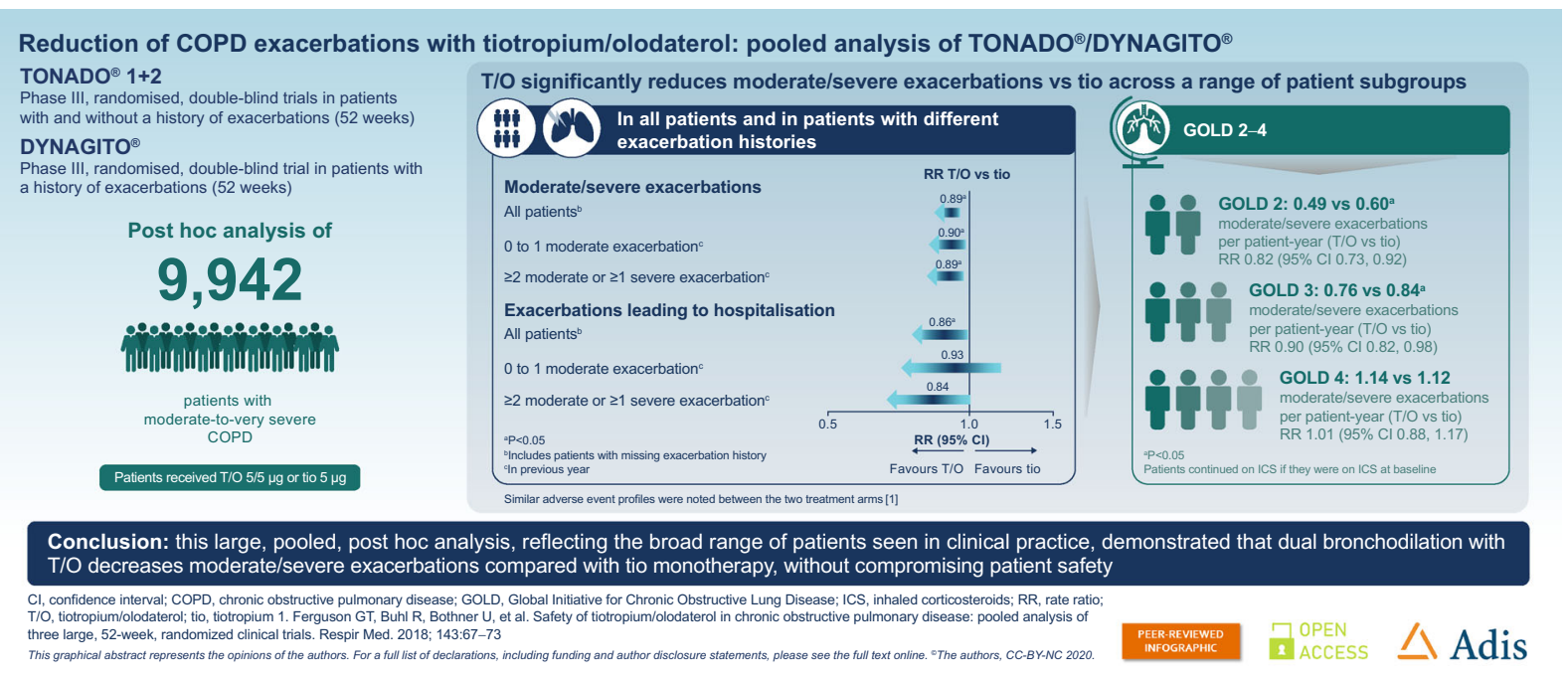


Keywords: COPD; Exacerbation; Hospitalisation

\section{Key Summary Points}

Why carry out this study?

In the DYNAGITO study, tiotropium/ olodaterol reduced the rate of exacerbations in patients with chronic obstructive pulmonary disease (COPD) compared with tiotropium but the reduction did not achieve statistical significance, possibly as a result of the statistical method used; this prompted the need for further investigation in a larger population.

We pooled data from almost 10,000 patients with moderate-to-very severe COPD from three 1-year studies in order to understand the impact of treatment with tiotropium/olodaterol relative to tiotropium on exacerbation rates across a range of patient types and COPD disease severities.

\section{What was learned from the study?}

This post hoc analysis demonstrated that dual bronchodilation with the long-acting muscarinic antagonist/long-acting $\beta_{2^{-}}$ agonist tiotropium/olodaterol reduces moderate/severe exacerbations and exacerbations leading to hospitalisation compared with tiotropium.

Reductions in moderate/severe exacerbations were seen in a range of patient subgroups, including Global Initiative for Chronic Obstructive Lung Disease stage 2-3 patients, in patients with varying exacerbation histories, and in patients receiving an inhaled corticosteroid at baseline.

These results support the use of dual bronchodilation with tiotropium/ olodaterol in a broad range of patients, reflective of patients with COPD seen in clinical practice.

\section{INTRODUCTION}

Chronic obstructive pulmonary disease (COPD) is a multidimensional, progressive condition characterised by persistent airflow obstruction, worsening dyspnoea and respiratory failure [1, 2]. Exacerbations, defined as periods of acute worsening of COPD symptoms that result in additional therapy, are a hallmark of COPD [1]. They are more prevalent in patients with more severe COPD, and are associated with an increased rate of lung function decline, worse quality of life, increased mortality, increased frequency of hospitalisations and higher healthcare costs [3-6]. Even in patients with milder forms of COPD, where exacerbations are less frequent, they still impose a significant burden [6, 7]. Therefore, effective management and prevention of exacerbations represents an important clinical challenge.

A prior history of exacerbations is the most reliable predictor of future exacerbations [7], and, consequently, the 2020 Global Initiative for Chronic Obstructive Lung Disease (GOLD) strategy report recommends that exacerbation history is used to guide treatment choice [1]. For patients with recurrent exacerbations on longacting bronchodilator monotherapy with longacting muscarinic antagonists (LAMAs) or longacting $\beta_{2}$-agonists (LABAs), escalation to a LAMA/LABA or LABA/inhaled corticosteroid (ICS) combination is recommended [1].

The American Thoracic Society (ATS) strongly recommends LABA/LAMA dual therapy over LABA or LAMA monotherapy in patients who experience dyspnoea or exercise intolerance, on the basis of improved critical outcomes with dual therapy [8]. Treatment with the LAMA/LABA fixed-dose combination tiotropium/olodaterol has demonstrated improvements in lung function, health-related quality of life and exercise capacity $[9,10]$. In addition, recent post hoc analyses showed that treatment escalation to tiotropium/olodaterol resulted in significant improvements in lung function, health status and breathlessness compared with tiotropium alone in patients who were receiving only LAMA monotherapy at study entry [11] and in patients who were maintenance-naïve at baseline [12]. Furthermore, there is evidence that LAMA/LABA 
can reduce exacerbations in patients with COPD compared with either agent alone or versus LABA/ ICS $[8,13-15]$. In the DYNAGITO ${ }^{\circledR}$ trial, the rate of moderate and severe exacerbations was lower with tiotropium/olodaterol compared with tiotropium $(P=0.0498)$; however, the results did not meet the targeted 0.01 significance level [13]. Expert analysis suggests that the primary statistical methodology used in the study was flawed, using a crude analysis rather than adjusting for baseline covariates [16]. Although the reduction in exacerbation rate was smaller than anticipated in DYNAGITO, there were larger improvements in some subgroups of patients, suggesting the need for further investigation in a larger population.

In order to better understand the impact of tiotropium/olodaterol on exacerbation rates across a range of COPD disease severities, we pooled data from almost 10,000 patients with moderate-to-very severe COPD from three 1-year studies: two phase III trials in patients with and without a history of exacerbations in the previous year $\left(\right.$ TONADO $\left.^{\circledR} 1+2\right)$ and a large phase III trial in patients with a history of exacerbations in the previous year (DYNAGITO) [9, 13]. In both trials, patients continued with ICS if they were taking them at baseline. As severe exacerbations are less frequently reported in the clinical trial setting, large patient numbers are required to demonstrate a meaningful change in outcomes. Using this large data set, we compared the effect of dual bronchodilation with tiotropium/olodaterol $5 / 5 \mu \mathrm{g}$ with tiotropium $5 \mu \mathrm{g}$ on moderate/severe exacerbations and exacerbations leading to hospitalisation.

Additionally, the large size of this patient cohort allowed detection of effects in patient subgroups, including those with low and high exacerbation history, GOLD stage 2-4 disease (using forced expiratory volume in $1 \mathrm{~s}\left[\mathrm{FEV}_{1}\right]$ to prognostically group patients according to the severity of their airflow limitation [1]), and in patients with and without baseline ICS use.

\section{METHODS}

\section{Study Design}

Detailed methodologies of TONADO and DYNAGITO have been published previously
$[9,13] . \quad$ The TONADO trials $[1237.5$ (NCT01431274) and 1237.6 (NCT01431287)] included a total of 5162 patients and were two replicate, 52-week, randomised, double-blind, parallel-group, phase III trials that compared tiotropium/olodaterol $(2.5 / 5 \mu \mathrm{g}$ and $5 / 5 \mu \mathrm{g})$ with the monocomponents tiotropium $(2.5 \mu \mathrm{g}$ and $5 \mu \mathrm{g})$ and olodaterol $(5 \mu \mathrm{g})$ in patients with moderate-to-very severe COPD, with or without previous exacerbations [9].

The DYNAGITO trial [1237.16 (NCT02296138)] included a total of 7880 patients and was a 52-week, phase III, randomised, double-blind, active-controlled, parallel-group trial in which patients with moderate-to-very severe COPD and a history of exacerbations were assigned to receive either tiotropium/olodaterol $(5 / 5 \mu \mathrm{g})$ or tiotropium $(5 \mu \mathrm{g})$ [13].

This post hoc analysis pooled data from the tiotropium/olodaterol $5 / 5 \mu \mathrm{g}$ and tiotropium $5 \mu \mathrm{g}$ arms of the TONADO and DYNAGITO studies. The study protocols were reviewed and approved by the independent ethics committees and/or institutional review boards of the participating centres. The studies were conducted in accordance with the Declaration of Helsinki and Good Clinical Practice guidelines. Patients in these studies provided written informed consent.

\section{Patients}

Patients with COPD aged 40 years or more, a smoking history of greater than 10 pack-years and post-bronchodilator $\mathrm{FEV}_{1} /$ forced vital capacity less than $70 \%$ were recruited into the TONADO and DYNAGITO trials. In TONADO, patients were eligible for the study if they had post-bronchodilator $\mathrm{FEV}_{1}<80 \%$ predicted, whereas in DYNAGITO the eligibility criteria included post-bronchodilator $\mathrm{FEV}_{1}<60 \%$ predicted and at least one moderate/severe exacerbation in the previous year. In brief, patients were excluded from these trials if they had a recent history of myocardial infarction or a diagnosis of thyrotoxicosis or life-threatening cardiac arrhythmia (more detail on exclusion criteria has been published previously $[9,13])$. 
GOLD 1 patients were included in the TONADO and DYNAGITO trials. They represent a small proportion of the total number of patients recruited and may reflect enrolling errors.

\section{Definition of Moderate and Severe COPD Exacerbations}

COPD exacerbations were defined as a complex of lower respiratory events/symptoms (increase or new onset) related to underlying COPD with duration of 3 days or more and requiring a prescription of antibiotics and/or systemic steroids and/or hospitalisation (DYNAGITO trial), or a prescription of antibiotics and/or systemic steroids and/or newly prescribed maintenance respiratory medications (TONADO trials). A complex of lower respiratory events/symptoms is defined as at least two of the following: shortness of breath, sputum production (volume), change in sputum colour, cough, wheezing or chest tightness.

Moderate exacerbations were classified as those requiring an exacerbation-related prescription of oral corticosteroids and/or antibiotics, but not requiring hospitalisation. Severe exacerbations were classified as exacerbations requiring hospitalisation, including emergency room visits.

\section{Subgroups of Interest}

For this post hoc analysis, data were pooled to assess the effect of tiotropium/olodaterol versus tiotropium on moderate/severe exacerbations and exacerbations leading to hospitalisation in the following subgroups: low (0-1 moderate exacerbation in 12 months prior to trial entry) and high exacerbation history (at least two moderate or at least one severe exacerbation in 12 months prior to trial entry); exacerbation history according to 0 or 1 exacerbation in 12 months prior to trial entry; GOLD stage 2, 3 and 4; and those with and without baseline ICS use. GOLD stage 1 patients were included within the GOLD stage 2 subgroup. An exploratory analysis was also conducted on low (below the median) and high (median or higher) symptomatic patients, assessed by St. George's Respiratory Questionnaire (SGRQ).

\section{Statistical Analysis}

To ensure comparability with data reported from other studies $[14,15,17]$, the exacerbation rates in this post hoc analysis were analysed using a negative binomial model adjusted for treatment, study, ICS use at baseline, region, GOLD stage and smoking status as fixed effects, and baseline SGRQ and number of exacerbations in previous year as covariates. All $P$ values are nominal. The duration of an event was not included in the calculation of a patient's exposure. In the subgroup analysis, the corresponding subgroup was excluded from the model as a covariate.

\section{RESULTS}

\section{Baseline Demographics}

A total of 9942 patients randomised to receive treatment with either tiotropium/olodaterol $(n=4968)$ or tiotropium $(n=4974)$ in the TONADO and DYNAGITO studies were pooled in this post hoc analysis. Baseline demographics were similar across treatment groups (Table 1). The majority of patients were male (tiotropium $72.3 \%$; tiotropium/olodaterol 70.8\%), and slightly over one-third were current smokers (Table 1; see Fig. 1 for patient disposition).

\section{Efficacy}

\section{Exacerbation Rates in the Pooled Population}

In the pooled population, there was a significantly lower rate of moderate/severe exacerbations with tiotropium/olodaterol (0.68 per patient-year) than tiotropium (0.77 per patientyear) (rate ratio (RR) vs. tiotropium $0.89 ; 95 \%$ confidence interval (CI) $0.84,0.95 ; P=0.0003$; Fig. 2a). There were also significantly fewer exacerbations requiring hospitalisation with tiotropium/olodaterol (0.11 per patient-year) than tiotropium (0.13 per patient-year) (RR vs. 
Table 1 Patient baseline characteristics from TONADO/ DYNAGITO

\begin{tabular}{|c|c|c|}
\hline & \multicolumn{2}{|l|}{ Pooled data } \\
\hline & $\begin{array}{l}\text { Tiotropium/ } \\
\text { olodaterol } 5 / 5 \mu \mathrm{g} \\
(n=4968)\end{array}$ & $\begin{array}{l}\text { Tiotropium } \\
5 \mu \mathrm{g} \\
(n=4974)\end{array}$ \\
\hline Male, $n(\%)$ & $3518(70.8)$ & $3596(72.3)$ \\
\hline $\begin{array}{l}\text { Mean age, } \\
\text { years } \pm S D\end{array}$ & $66.0 \pm 8.5$ & $65.8 \pm 8.6$ \\
\hline \multicolumn{3}{|c|}{ Smoking status, $n(\%)$} \\
\hline Ex-smoker & $3134(63.1)$ & $3125(62.8)$ \\
\hline Current smoker & $1834(36.9)$ & $1848(37.2)$ \\
\hline \multicolumn{3}{|l|}{ GOLD stage, $n(\%)$} \\
\hline GOLD 1 & $27(0.5)$ & $21(0.4)$ \\
\hline GOLD 2 & $1850(37.2)$ & $1953(39.3)$ \\
\hline GOLD 3 & $2436(49.0)$ & $2398(48.2)$ \\
\hline GOLD 4 & $644(13.0)$ & $595(12.0)$ \\
\hline Missing & $11(0.2)$ & $7(0.1)$ \\
\hline \multicolumn{3}{|l|}{ Post-bronchodilator } \\
\hline $\mathrm{FEV}_{1}, \mathrm{~L} \pm \mathrm{SD}$ & $1.212 \pm 0.418$ & $1.233 \pm 0.417$ \\
\hline $\begin{array}{l}\mathrm{FEV}_{1} \% \\
\text { predicted } \pm \mathrm{SD}\end{array}$ & $45.6 \pm 34.2$ & $45.6 \pm 12.7$ \\
\hline $\begin{array}{l}\text { Baseline } \\
\text { pulmonary } \\
\text { medication, } \\
n(\%)\end{array}$ & $4710(94.8)$ & $4703(94.6)$ \\
\hline SAMA & $922(18.6)$ & $908(18.3)$ \\
\hline SABA & $2986(60.1)$ & $2944(59.2)$ \\
\hline LAMA & $2837(57.1)$ & $2839(57.1)$ \\
\hline LABA & $3655(73.6)$ & $3645(73.3)$ \\
\hline $\mathrm{LAMA}+\mathrm{LABA}$ & $506(10.2)$ & $516(10.4)$ \\
\hline Any ICS & $3277(66.0)$ & $3229(64.9)$ \\
\hline Xanthines & $654(13.2)$ & $676(13.6)$ \\
\hline \multicolumn{3}{|c|}{ Medical history and pre-existing conditions, $n$ (\%) } \\
\hline $\begin{array}{l}\text { Cardiovascular } \\
\text { medication }\end{array}$ & $2997(60.3)$ & $2941(59.1)$ \\
\hline
\end{tabular}

Table 1 continued

\begin{tabular}{lll}
\hline & \multicolumn{1}{l}{ Pooled data } & \\
\cline { 2 - 3 } & $\begin{array}{l}\text { Tiotropium/ } \\
\text { olodaterol } \mathbf{5 / 5} \boldsymbol{\mu g} \\
(\boldsymbol{n}=\mathbf{4 9 6 8})\end{array}$ & $\begin{array}{l}\text { Tiotropium } \\
\mathbf{5} \boldsymbol{\mu g} \\
(\boldsymbol{n}=\mathbf{4 9 7 4})\end{array}$ \\
\hline $\begin{array}{l}\text { Cardiovascular } \\
\text { history }\end{array}$ & $1290(26.0)$ & $1275(25.6)$ \\
$\begin{array}{l}\text { Ischaemic heart } \\
\text { disease }\end{array}$ & $844(17.0)$ & $839(16.9)$ \\
$\begin{array}{l}\text { Cardiac } \\
\text { arrhythmias }\end{array}$ & $483(9.7)$ & $429(8.6)$ \\
Cerebrovascular & $247(5.0)$ & $219(4.4)$ \\
event & & $2701(54.3)$ \\
Hypertension & $2758(55.5)$ & $764(15.4)$ \\
\hline \begin{tabular}{l} 
Diabetes mellitus \\
\hline
\end{tabular} & $718(14.5)$ &
\end{tabular}

$F E V_{1}$ forced expiratory volume in $1 \mathrm{~s}$, GOLD Global Initiative for Chronic Obstructive Lung Disease, ICS inhaled corticosteroids, $L A B A$ long-acting $\beta_{2}$-agonist, $L A M A$ long-acting muscarinic antagonist, $S A B A$ shortacting $\beta_{2}$-agonist, $S A M A$ short-acting muscarinic antagonist, $S D$ standard deviation

a TONADO: System Organ Class "Cardiac disorders" or history of myocardial infarction, cerebrovascular accident, cardiac arrhythmia or heart failure New York Heart Association class III or IV; DYNAGITO: history of cardiac arrhythmia, ischaemic heart disease, cardiac arrest, cardiac failure, haemorrhagic or ischaemic cerebrovascular conditions, transient cerebrovascular event or transient ischaemic attack

tiotropium $0.86 ; 95 \%$ CI $0.75,0.99 ; P=0.0380$; Fig. 2b).

\section{Exacerbation Rates Stratified by Exacerbation History}

In patients with no exacerbations in the previous year, there was no significant reduction in moderate/severe exacerbations with tiotropium/olodaterol compared with tiotropium; however, the exacerbation rates during the study were very low in this group (Fig. 2a). In patients with one moderate exacerbation in the 


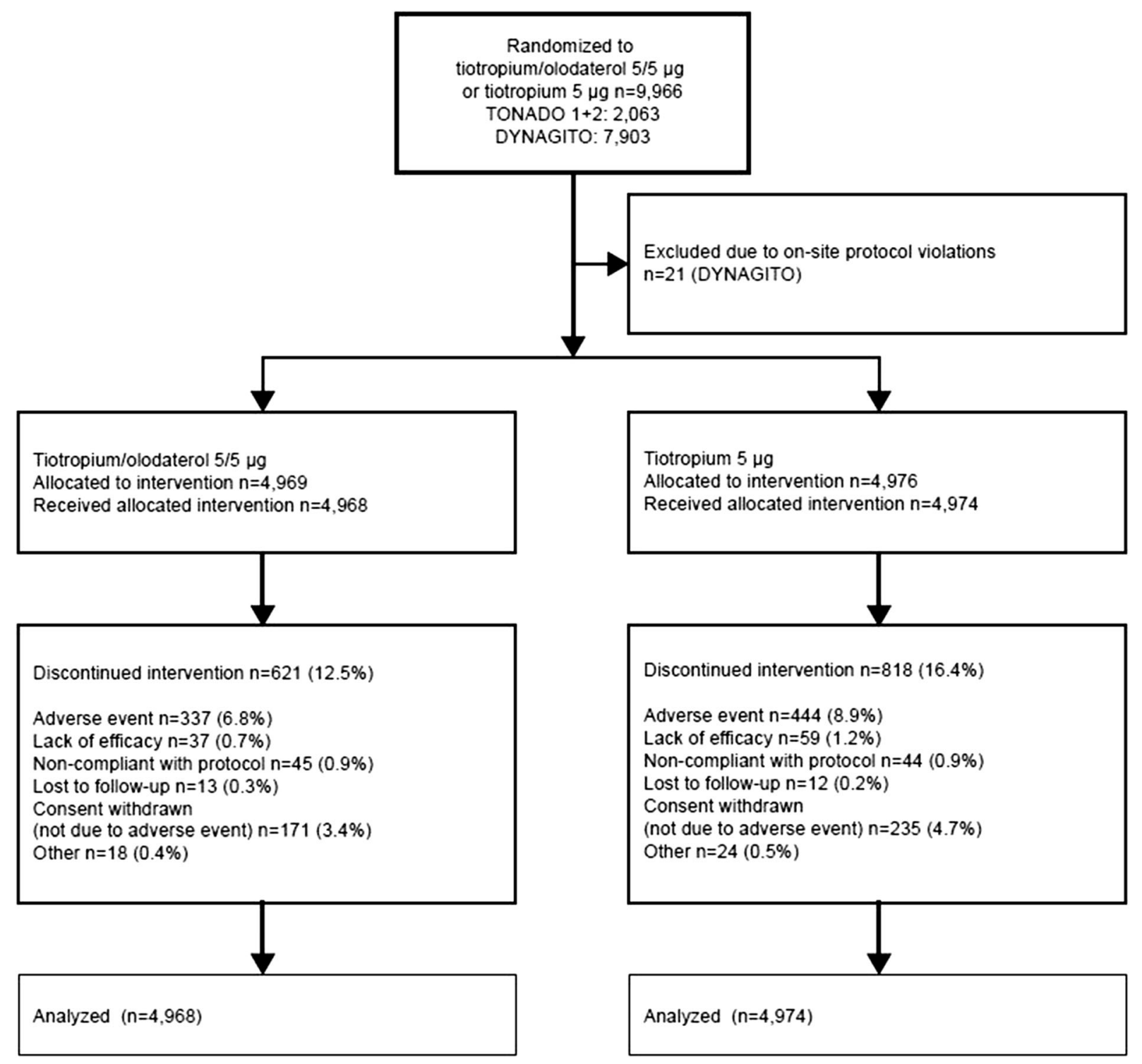

Fig. 1 Patient disposition (pooled population). Ferguson et al. [18]. (c) 2018 The Authors. Published by Elsevier Ltd. This work is licensed under a Creative Commons Attribution Non-Commercial-No Derivatives (CC BY NC ND 4.0) License

previous year, the rate of moderate/severe exacerbations was significantly reduced with tiotropium/olodaterol (0.60 per patient-year) compared with tiotropium $(0.68$ per patientyear) (RR vs. tiotropium 0.88; 95\% CI 0.80, 0.97; $P=0.0088$.

In patients with $0-1$ moderate exacerbation in the previous year, the rate of moderate/severe exacerbations was significantly reduced with tiotropium/olodaterol (0.54 per patient-year) compared with tiotropium (0.60 per patient- year) (RR vs. tiotropium 0.90; 95\% CI 0.82, 0.98; $P=0.0187$; Fig. 2a). The same was true for patients with at least two moderate or at least one severe exacerbation(s) in the previous year, with significant reductions observed with tiotropium/olodaterol (0.97 per patient-year) compared with tiotropium (1.09 per patientyear) (RR vs. tiotropium 0.89; 95\% CI 0.82, 0.97; $P=0.0096)$. As expected, the event rate was higher among patients who had experienced at least two moderate or at least one severe 
(A)
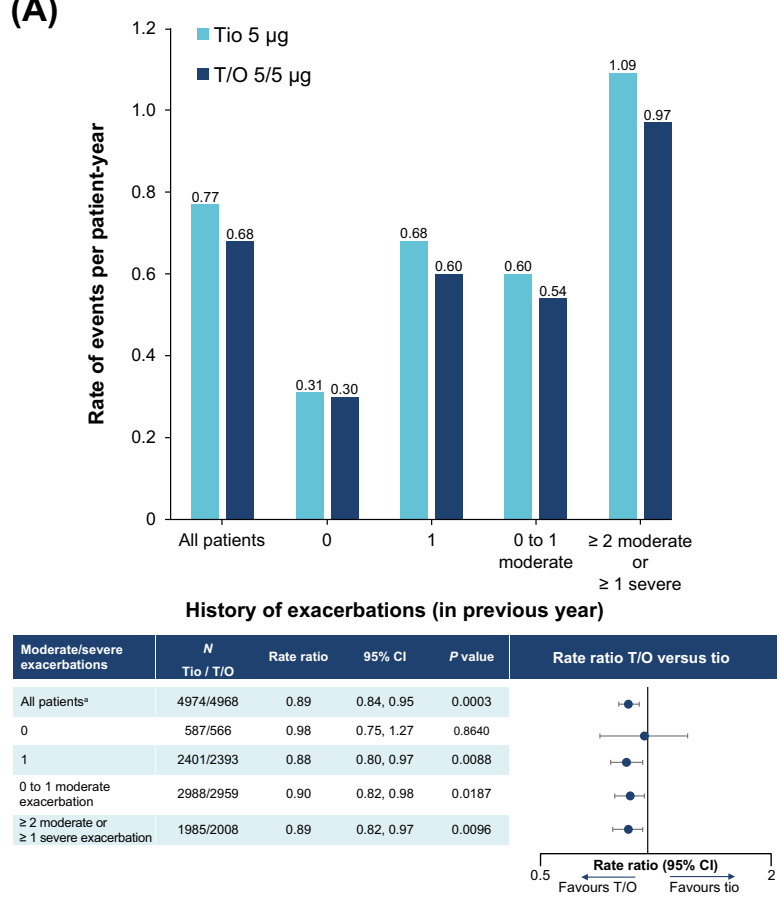

Fig. 2 a Exacerbation rates in all patients and by exacerbation history; and $\mathbf{b}$ exacerbation rates leading to hospitalisation in all patients and by exacerbation history.

exacerbation in the previous year compared with patients with $0-1$ moderate exacerbation in the previous year.

The overall rate of exacerbations leading to hospitalisation was low, with no significant change with tiotropium/olodaterol compared with tiotropium in the subgroups stratified by exacerbation history. The exacerbations leading to hospitalisation were lower in patients with at least two moderate or at least one severe exacerbation(s) in the previous year with tiotropium/olodaterol $(0.20$ per patient-year $)$ compared with tiotropium $(0.24$ per patientyear) (RR vs. tiotropium 0.84; 95\% CI 0.70, 1.00; $P=0.0541$; Fig. 2b).

\section{Exacerbation Rates by GOLD Stage}

In patients with GOLD 2 COPD, the rate of exacerbations was significantly lower with tiotropium/olodaterol (0.49 per patient-year) compared with tiotropium $(0.60$ per patientyear) (RR vs. tiotropium $0.82 ; 95 \%$ CI $0.73,0.92$; $P=0.0004$; Table 2). There was also a
(B)
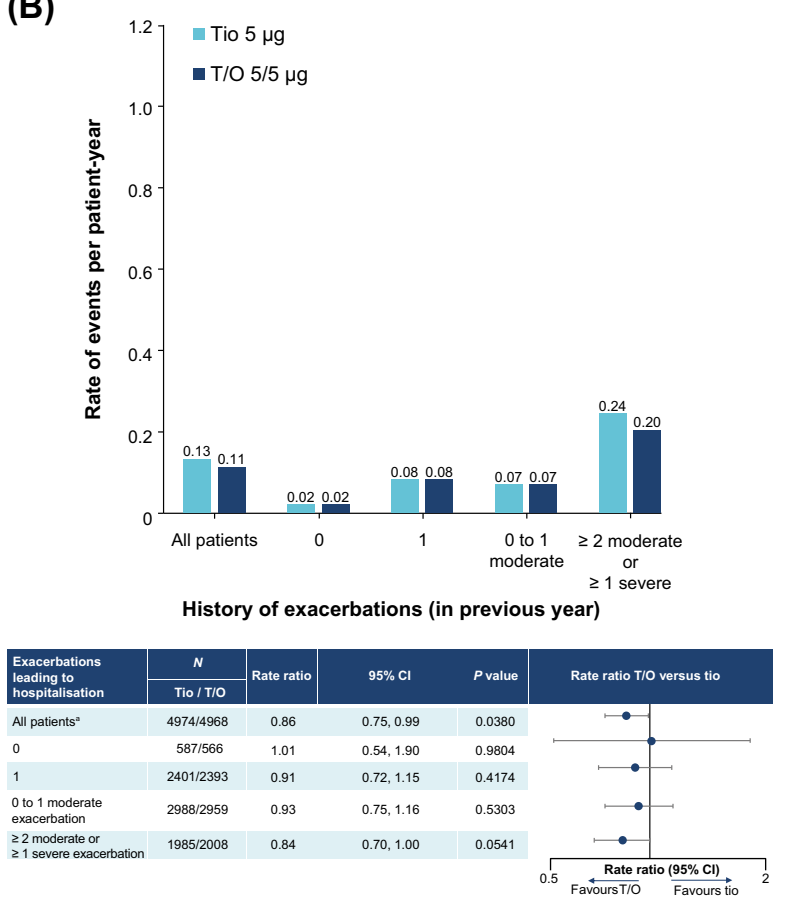

CI confidence interval, T/O tiotropium/olodaterol, Tio

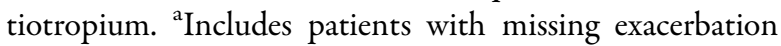
history

significantly lower rate of exacerbations in patients with GOLD 3 COPD with tiotropium/ olodaterol (0.76 per patient-year) compared with tiotropium (0.84 per patient-year) (RR vs. tiotropium 0.90; 95\% CI 0.82, 0.98; $P=0.0174$ ). In patients with GOLD 4 COPD, there was a negligible difference between tiotropium/olodaterol and tiotropium, and this result was not statistically significant. Patients from all GOLD stages had a reduced rate of exacerbations leading to hospitalisation with tiotropium/olodaterol compared with tiotropium, although the differences were not statistically significant (Table 2).

\section{Exacerbation Rates by ICS Use}

Among patients with baseline ICS use (i.e., 3277 patients $(66.0 \%)$ in the tiotropium/olodaterol arm and 3229 patients $(64.9 \%)$ in the tiotropium arm), there was a significantly lower rate of moderate/severe exacerbations with tiotropium/olodaterol ( 0.79 per patient-year) than with tiotropium (0.90 per patient-year) (RR vs. 
Table 2 Exacerbation rates by GOLD stage

\begin{tabular}{|c|c|c|c|c|c|}
\hline \multirow[t]{2}{*}{ GOLD stage } & \multirow{2}{*}{$\begin{array}{l}\text { Patients on tiotropium/ } \\
\text { olodaterol/tiotropium }(N)\end{array}$} & \multicolumn{2}{|c|}{ Rate of events per patient-year (SE) } & \multirow[t]{2}{*}{ Rate ratio $(95 \% \mathrm{CI})$} & \multirow[t]{2}{*}{$P$ value } \\
\hline & & Tiotropium/olodaterol & Tiotropium & & \\
\hline \multicolumn{6}{|c|}{ Moderate/severe exacerbations } \\
\hline GOLD stage 2 & $1877 / 1974$ & $0.49(0.042)$ & $0.60(0.039)$ & $0.82(0.73,0.92)$ & 0.0004 \\
\hline GOLD stage 3 & $2436 / 2398$ & $0.76(0.032)$ & $0.84(0.032)$ & $0.90(0.82,0.98)$ & 0.0174 \\
\hline GOLD stage 4 & $644 / 595$ & $1.14(0.051)$ & $1.12(0.056)$ & $1.01(0.88,1.17)$ & 0.8493 \\
\hline \multicolumn{6}{|c|}{ Exacerbations leading to hospitalisation } \\
\hline GOLD stage 2 & $1877 / 1974$ & $0.06(0.116)$ & $0.07(0.107)$ & $0.79(0.59,1.06)$ & 0.1218 \\
\hline GOLD stage 3 & $2436 / 2398$ & $0.14(0.071)$ & $0.16(0.071)$ & $0.88(0.73,1.07)$ & 0.1921 \\
\hline GOLD stage 4 & $644 / 595$ & $0.26(0.104)$ & $0.30(0.107)$ & $0.86(0.65,1.13)$ & 0.2716 \\
\hline
\end{tabular}

$C I$ confidence interval, GOLD Global Initiative for Chronic Obstructive Lung Disease, SE standard error

tiotropium 0.88; 95\% CI 0.82, 0.95; $P=0.0005$ ). These patients also had a significantly reduced rate of exacerbations leading to hospitalisation with tiotropium/olodaterol compared with tiotropium $(P=0.0063$; Table 3$)$. In patients with no ICS use at baseline, the rate of moderate/severe exacerbations was 0.51 per patientyear with tiotropium/olodaterol compared with 0.56 per patient-year with tiotropium $(P=0.1647)$. In these patients, there was no difference between treatment groups in the rate of exacerbations leading to hospitalisation (Table 3). Overall, the rate of exacerbations was higher in patients with baseline ICS use than in those with no baseline ICS use.

\section{Exploratory Analysis of Exacerbations Rates by Baseline SGRQ}

In the SGRQ subgroup analysis, irrespective of SGRQ score at baseline, treatment with tiotropium/olodaterol (below the median, 0.54 per patient-year; median or higher, 0.85 per patient-year) was associated with a significantly lower rate of exacerbations in comparison with treatment with tiotropium (below the median, 0.63 per patient-year; RR 0.86 ; 95\% CI 0.78 , 0.95 ; median or higher, 0.93 per patient-year; RR 0.91; 95\% CI 0.84, 0.99; Supplementary Table 1). Patients with a lower SGRQ score had significantly fewer exacerbations leading to hospitalisation with tiotropium/olodaterol compared with tiotropium (below the median,

Table 3 Exacerbation rates by ICS use

\begin{tabular}{|c|c|c|c|c|c|}
\hline \multirow[t]{2}{*}{ ICS use } & \multirow{2}{*}{$\begin{array}{l}\text { Patients on tiotropium/ } \\
\text { olodaterol/tiotropium }(N)\end{array}$} & \multicolumn{2}{|c|}{ Rate of events per patient-year (SE) } & \multirow[t]{2}{*}{ Rate ratio $(95 \% \mathrm{CI})$} & \multirow[t]{2}{*}{$P$ value } \\
\hline & & Tiotropium/olodaterol & Tiotropium & & \\
\hline \multicolumn{6}{|c|}{ Moderate/severe exacerbations } \\
\hline Yes & $3277 / 3229$ & $0.79(0.026)$ & $0.90(0.026)$ & $0.88(0.82,0.95)$ & 0.0005 \\
\hline No & $1691 / 1745$ & $0.51(0.048)$ & $0.56(0.047)$ & $0.91(0.80,1.04)$ & 0.1647 \\
\hline \multicolumn{6}{|c|}{ Exacerbations leading to hospitalisation } \\
\hline Yes & $3277 / 3229$ & $0.13(0.061)$ & $0.16(0.059)$ & $0.80(0.69,0.94)$ & 0.0063 \\
\hline No & $1691 / 1745$ & $0.08(0.110)$ & $0.08(0.113)$ & $1.03(0.77,1.38)$ & 0.8336 \\
\hline
\end{tabular}

$C I$ confidence interval, ICS inhaled corticosteroid, $S E$ standard error 
RR 0.70; 95\% CI 0.55, 0.89; Supplementary Table 1).

\section{Safety}

Safety data from the pooled population have been published previously [18]. In brief, the proportion of patients discontinuing treatment was lower with tiotropium/olodaterol (12.5\%) compared with tiotropium (16.4\%). This was mainly due to a lower proportion of patients with adverse events leading to discontinuation with tiotropium/olodaterol (5.9\%) than with tiotropium (7.9\%). The most frequently reported adverse event leading to discontinuation was COPD exacerbation; this was reported in fewer patients with tiotropium/olodaterol than tiotropium $(2.1 \%$ vs. $3.1 \%)$. The incidence of pneumonia was the same in both groups (4.5\%). Therapy with tiotropium/olodaterol had a similar safety profile to tiotropium.

\section{DISCUSSION}

This post hoc analysis demonstrated that dual bronchodilation with the LAMA/LABA tiotropium/olodaterol reduces moderate-to-severe exacerbations compared with tiotropium, even in patients with infrequent exacerbation history (0-1 moderate exacerbation in previous year). Improvements were seen in GOLD stages 2-3 and in patients taking ICS at baseline. Tiotropium/olodaterol also decreased the rate of exacerbations leading to hospitalisation versus tiotropium, although the findings did not reach statistical significance in all subgroups. Exacerbations leading to hospitalisation were most evident in frequent exacerbators; however, low event rates in some of the subgroups limit interpretation in these cases.

Combining data from the TONADO and DYNAGITO trials resulted in a large pooled data set of patients with COPD treated with tiotropium/olodaterol and tiotropium, covering a broad range of phenotypes seen in clinical practice.

Subgroup analyses showed that the reduction in moderate/severe exacerbations was largely consistent across the disease spectrum (with the exception of GOLD stage 4 and nonICS users), with a consistent magnitude of reduction across different severity grades of exacerbation history and lung function. When the data were analysed by prior history of exacerbations, a significant reduction in moderate/severe exacerbations was observed with tiotropium/olodaterol compared with tiotropium in all subgroups apart from the group of patients with no exacerbations in the previous year. As expected, the event rate was higher among patients with a high versus a low exacerbation history. This is consistent with previous studies, which indicates that the recurrence of exacerbations is linked to the history of prior exacerbations [3].

In patients with GOLD 2 and 3 COPD, dual bronchodilation with tiotropium/olodaterol reduced the rate of moderate/severe exacerbations to a greater degree than with tiotropium. The same effect was not observed in patients with GOLD 4 COPD. This observation may reflect the nature of exacerbations in more severe disease, although an effect due to inadequate statistical power cannot be ruled out.

A significant reduction in exacerbations was observed with tiotropium/olodaterol versus tiotropium in the prior ICS use group. This could be explained by the larger size of the subgroup and the number of events reported compared with the non-ICS subgroup. It should be noted that approximately two-thirds of patients in this pooled analysis were using an ICS at baseline, which likely reflects how patients are managed in clinical practice. In addition, as is typical for clinical studies in COPD, treatment escalation and de-escalation occurred in a proportion of patients in the dual therapy and monotherapy arms, respectively. Despite this, the model applied to our analysis accounts for the treatment patients received at baseline, and therefore this is not expected to have significantly influenced these results. These results underscore the rationale for adding LABA in this setting and demonstrate its benefits beyond improvements in lung function. This adds to the body of evidence supporting the overall benefits of LAMA/LABA versus LAMA in terms of improvements in lung function, quality of life and symptom reduction 
$[19,20]$. Although the reduction in moderateto-severe exacerbations was not statistically significant in this analysis in the non-ICS group, the effect size $(9 \%)$ was similar to the results seen in some of the other subgroups (12\% in ICS users, 10\% in GOLD 3 group), even though the sample size was smaller.

In addition, in the exploratory analysis by baseline SGRQ score, patients showed a reduction in moderate/severe exacerbations with tiotropium/olodaterol in comparison with tiotropium regardless of SGRQ burden. Of note, in terms of exacerbations leading to hospitalisation, patients with low SGRQ score at baseline had a significant decrease with tiotropium/olodaterol versus tiotropium, whereas those with high SGRQ score benefitted less.

It has been suggested that a combination of LAMA/LABA can result in a significant reduction in exacerbations for patients compared with LAMA or LABA monotherapy $[8,15]$. In the ATS COPD clinical practice guidelines, a pooled analysis of 15 studies that assessed exacerbation risk revealed a reduced risk with dual LAMA/LABA therapy versus monotherapy (risk ratio $0.80 ; 95 \%$ CI $0.69,0.92 ; P=0.002$ ) [8]. Although some of the individual studies from this meta-analysis reported significant reductions in the risk of exacerbations versus placebo [21-25], when comparing LAMA/LABA with monocomponents, only numerical reductions were reported, which did not reach statistical significance [13, 26-28]. However, many of these studies were not powered to detect a difference in exacerbation rates. The SPARK ${ }^{\circledR}$ study, which was powered to evaluate exacerbation risk, examined the effect of 1-year treatment with the LAMA/LABA combination glycopyrronium/indacaterol on the rate of moderate/severe exacerbations in 2224 patients with severe-to-very severe COPD. In this study, glycopyrronium/indacaterol reduced the adjusted annual rate of exacerbations versus glycopyrronium monotherapy by $12 \%$ [15].

Some limitations of the study are that it is a post hoc analysis and that there was no placebo group for reference. In addition, as ICS use was allowed, this makes the comparison of LAMA/ LABA versus LAMA more difficult. However, its strengths include the large patient population, which is broadly representative of clinical practice and enables assessment of exacerbation rates across a range of different subgroups, thus helping to inform management strategies for different subtypes of patients with COPD.

\section{CONCLUSION}

In this post hoc analysis of almost 10,000 patients pooled from the TONADO and DYNAGITO trials, reflecting the broad range of patients seen in clinical practice, tiotropium/ olodaterol decreased the rate of moderate/severe exacerbations compared with tiotropium, with reductions seen across a wide range of subgroups. This study supports the growing body of evidence showing the benefits of dual bronchodilation with tiotropium/olodaterol in patients with COPD.

\section{ACKNOWLEDGEMENTS}

Funding. TONADO ${ }^{\circledR} \quad 1+2$ and DYNAGITO $^{\circledR}$ were funded by Boehringer Ingelheim. Boehringer Ingelheim also paid the Rapid Service Fee for this article.

Medical Writing, Editorial, and other Assistance. Medical writing assistance, in the form of the preparation and revision of the manuscript, was supported financially by Boehringer Ingelheim and provided by Francesca Lomas at MediTech Media, under the authors' conceptual direction and based on feedback from the authors.

Authorship. All named authors meet the International Committee of Medical Journal Editors (ICMJE) criteria for authorship for this article, take responsibility for the integrity of the work as a whole, and have given their approval for this version to be published.

Disclosures. Jadwiga A. Wedzicha reports grants from Johnson and Johnson, other from Novartis, Boehringer Ingelheim, AstraZeneca and GSK, and grants from GSK, AstraZeneca, 
Boehringer Ingelheim, Novartis, and Chiesi, outside the submitted work. Roland Buhl reports grants to Mainz University and personal fees from Boehringer Ingelheim, GlaxoSmithKline, Novartis, and Roche, as well as personal fees from AstraZeneca, Chiesi, Cipla, Sanofi, and Teva, outside the submitted work. Dave Singh reports personal fees from Apellis, Cipla, Genentech, Peptinnovate and Skyepharma, and grants and personal fees from AstraZeneca, Boehringer Ingelheim, Chiesi, Glenmark, Merck, Mundipharma, Novartis, Pfizer, Pulmatrix, Teva, Theravance and Verona, outside the submitted work. Claus F. Vogelmeier reports grants and personal fees from AstraZeneca, Boehringer Ingelheim, Chiesi, GlaxoSmithKline, Grifols Mundipharma and Novartis, personal fees from Berlin Chemie/Menarini, CSL Behring and Teva, grants from German Federal Ministry of Education and Research (BMBF) Competence Network Asthma and COPD (ASCONET), and personal fees from Nuvaira and MedUpdate, outside the submitted work. Alberto de la $\mathrm{Hoz}$ and Wenqiong Xue are employees of Boehringer Ingelheim. Antonio Anzueto reports personal fees from GlaxoSmithKline, AstraZeneca and Boehringer Ingelheim, outside the submitted work. Peter M.A. Calverley reports grants and personal fees from GlaxoSmithKline, personal fees from AstraZeneca, Boehringer Ingelheim, Recipharm and Zambon and personal fees and other from Boehringer Ingelheim outside the submitted work.

Compliance with Ethics Guidelines. Both of the TONADO $^{\circledR}$ and DYNAGITO ${ }^{\circledR}$ studies were performed in accordance with the Declaration of Helsinki, International Conference on Harmonisation Harmonised Tripartite Guideline for Good Clinical Practice and local regulations. The protocols were approved by the authorities and the ethics committees of the respective institutions, and signed informed consent was obtained from all patients.

Prior Presentation. This manuscript is based on work previously presented as a poster at European Respiratory Society (ERS) International Congress, 28 September-02 October 2019, Madrid, Spain.
Data Availability. The data set used and analysed during the current study are available from the corresponding author on reasonable request. Before this request, users should get permission from the local ethics committee.

Open Access. This article is licensed under a Creative Commons Attribution-NonCommercial 4.0 International License, which permits any non-commercial use, sharing, adaptation, distribution and reproduction in any medium or format, as long as you give appropriate credit to the original author(s) and the source, provide a link to the Creative Commons licence, and indicate if changes were made. The images or other third party material in this article are included in the article's Creative Commons licence, unless indicated otherwise in a credit line to the material. If material is not included in the article's Creative Commons licence and your intended use is not permitted by statutory regulation or exceeds the permitted use, you will need to obtain permission directly from the copyright holder. To view a copy of this licence, visit http:// creativecommons.org/licenses/by-nc/4.0/.

\section{REFERENCES}

1. Global Initiative for Chronic Obstructive Lung Disease. Global strategy for the diagnosis, management, and prevention of chronic obstructive pulmonary disease (2020 report). 2019. https:// goldcopd.org/wp-content/uploads/2019/11/GOLD2020-REPORT-ver1.0wms.pdf. Accessed Feb 14, 2020.

2. Calverley P. Respiratory failure in chronic obstructive pulmonary disease. Eur Respir J. 2003;22(47 suppl):26s-30s.

3. Wedzicha JA, Singh R, Mackay AJ. Acute COPD exacerbations. Clin Chest Med. 2014;35(1):157-63.

4. Donaldson GC, Seemungal TA, Bhowmik A, Wedzicha JA. Relationship between exacerbation frequency and lung function decline in chronic obstructive pulmonary disease. Thorax. 2002;57(10):847-52.

5. Seemungal TAR, Donaldson GC, Paul EA, Bestall JC, Jeffries DJ, Wedzicha JA. Effect of exacerbation on 
quality of life in patients with chronic obstructive pulmonary disease. Am J Respir Crit Care Med. 1998;157(5):1418-22.

6. Qureshi H, Sharafkhaneh A, Hanania NA. Chronic obstructive pulmonary disease exacerbations: latest evidence and clinical implications. Ther Adv Chronic Dis. 2014;5(5):212-27.

7. Hurst JR, Vestbo J, Anzueto A, et al. Susceptibility to exacerbation in chronic obstructive pulmonary disease. N Engl J Med. 2010;363(12):1128-38.

8. Nici L, Mammen MJ, Charbek E, et al. Pharmacologic management of COPD: an official American Thoracic Society clinical practice guideline. Am J Respir Crit Care Med. 2020;201(9):e56-e69.

9. Buhl R, Maltais F, Abrahams R, et al. Tiotropium and olodaterol fixed-dose combination versus mono-components in COPD (GOLD 2-4). Eur Respir J. 2015;45(4):969-79.

10. Troosters T, Maltais F, Leidy N, et al. Effect of bronchodilation, exercise training, and behavior modification on symptoms and physical activity in chronic obstructive pulmonary disease. Am J Respir Crit Care Med. 2018;198(8):1021-32.

11. Buhl R, Singh D, de la Hoz A, Xue W, Ferguson GT. Benefits of tiotropium/olodaterol compared with tiotropium in patients with COPD receiving only LAMA at baseline: pooled analysis of the TONADO ${ }^{\circledR}$ and OTEMTO ${ }^{\circledR}$ studies. Adv Ther. 2020. https://doi. org/10.1007/s12325-020-01373-3.

12. Buhl R, de la Hoz A, Xue W, Singh D, Ferguson GT. Efficacy of tiotropium/olodaterol compared with tiotropium as a first-line maintenance treatment in patients with COPD who are naïve to LAMA, LABA and ICS: pooled analysis of four clinical trials. Adv Ther. 2020. https://doi.org/10.1007/s12325-02001411-0.

13. Calverley PMA, Anzueto AR, Carter K, et al. Tiotropium and olodaterol in the prevention of chronic obstructive pulmonary disease exacerbations (DYNAGITO): a double-blind, randomised, parallel-group, active-controlled trial. Lancet Respir Med. 2018;6(5):337-44.

14. Wedzicha JA, Banerji D, Chapman KR, et al. Indacaterol-glycopyrronium versus salmeterol-fluticasone for COPD. N Engl J Med. 2016;374(23): 2222-34.

15. Wedzicha JA, Decramer M, Ficker JH, et al. Analysis of chronic obstructive pulmonary disease exacerbations with the dual bronchodilator QVA149 compared with glycopyrronium and tiotropium (SPARK): a randomised, double-blind, parallel- group study. Lancet Respir Med. 2013;1(3): 199-209.

16. Suissa S. Improving the efficiency of randomized trials: the DYNAGITO example. COPD. 2019:1-3.

17. Lipson DA, Barnhart F, Brealey N, et al. Once-daily single-inhaler triple versus dual therapy in patients with COPD. N Engl J Med. 2018;378(18):1671-80.

18. Ferguson GT, Buhl R, Bothner U, et al. Safety of tiotropium/olodaterol in chronic obstructive pulmonary disease: pooled analysis of three large, 52-week, randomized clinical trials. Respir Med. 2018;143:67-73.

19. Ferguson GT, Karpel J, Bennett N, et al. Effect of tiotropium and olodaterol on symptoms and patient-reported outcomes in patients with COPD: results from four randomised, double-blind studies. NPJ Prim Care Respir Med. 2017;27(1):7.

20. Singh D, Ferguson GT, Bolitschek J, et al. Tiotropium + olodaterol shows clinically meaningful improvements in quality of life. Respir Med. 2015;109(10):1312-9.

21. Celli B, Crater G, Kilbride S, et al. Once-daily umeclidinium/vilanterol 125/25 mcg in COPD: a randomized, controlled study. Chest. 2014;145(5): 981-91.

22. D'Urzo A, Rennard S, Kerwin E, et al. A randomised double-blind, placebo-controlled, long-term extension study of the efficacy, safety and tolerability of fixed-dose combinations of aclidinium/formoterol or monotherapy in the treatment of chronic obstructive pulmonary disease. Respir Med. 2017;125:39-48.

23. Singh D, Jones PW, Bateman ED, et al. Efficacy and safety of aclidinium bromide/formoterol fumarate fixed-dose combinations compared with individual components and placebo in patients with COPD (ACLIFORM-COPD): a multicentre, randomised study. BMC Pulm Med. 2014;14(1):178.

24. Donohue JF, Maleki-Yazdi MR, Kilbride S, Mehta R, Kalberg C, Church A. Efficacy and safety of oncedaily umeclidinium/vilanterol $62.5 / 25 \mathrm{mcg}$ in COPD. Respir Med. 2013;107(10):1538-46.

25. Vogelmeier C, Kardos P, Harari S, Gans SJ, Stenglein $\mathrm{S}$, Thirlwell J. Formoterol mono-and combination therapy with tiotropium in patients with COPD: a 6-month study. Respir Med. 2008;102(11):1511-20.

26. Hanania NA, Tashkin DP, Kerwin EM, et al. Longterm safety and efficacy of glycopyrrolate/formoterol metered dose inhaler using novel Co-Suspension $^{\mathrm{TM}}$ Delivery Technology in patients with 
chronic obstructive pulmonary disease. Respir Med. 2017;126:105-15.

27. Donohue JF, Soong W, Wu X, Shrestha P, Lei A. Long-term safety of aclidinium bromide/formoterol fumarate fixed-dose combination: results of a randomized 1-year trial in patients with COPD. Respir Med. 2016;116:41-8.
28. Ferguson GT, Taylor AF, Thach C, et al. Long-term maintenance bronchodilation with indacaterol/ glycopyrrolate versus indacaterol in moderate-tosevere COPD patients: the FLIGHT 3 study. Chronic Obstr Pulm Dis. 2016;3(4):716. 